Article

\title{
Spatiotemporal Patterns and Driving Forces of Urban Expansion in Coastal Areas: A Study on Urban Agglomeration in the Pearl River Delta, China
}

\author{
Yichen Yan ${ }^{1}$, Hongrun Ju ${ }^{1, *}$, Shengrui Zhang ${ }^{2, *}$ and Wei Jiang ${ }^{3}$ \\ 1 School of Tourism and Geography Science, Qingdao University, Qingdao 266071, China; yyc525geo@126.com \\ 2 Management College, Ocean University of China, Qingdao 266100, China \\ 3 China Institute of Water Resources and Hydropower Research, Beijing 100038, China; jiangwei@iwhr.com \\ * Correspondence: juhr@qdu.edu.cn (H.J.); zhangshengrui@ouc.edu.cn (S.Z.)
}

Received: 24 November 2019; Accepted: 20 December 2019; Published: 25 December 2019

\begin{abstract}
Since the beginning of the 21st century, the spatial pattern of urban expansion and the mechanism of urbanization in coastal areas have undergone significant changes. This study aims to reveal the spatiotemporal patterns of urban land expansion and analyze the dynamic driving forces of urban agglomeration in the Pearl River Delta of China from 2000 to 2015. The urban-land-expansion intensity index, expansion difference index, and fractal dimension were used to study how the urban land in this area was developed, and the geographical detector was applied to explore the relative importance, expansion intensity, and interactions of physical and socioeconomic factors. The results revealed that the urban-land-expansion intensity of the Pearl-River-Delta urban agglomerations exhibit a downward trend, while cities exhibited a trend of developing more coordinately from 2000 to 2015. Physical factors determined the direction and scale of urban development, and the urban land expansion in the Pearl-River-Delta urban agglomeration is mainly distributed in plain areas that have an elevation below $120 \mathrm{~m}$ and a slope less than $5^{\circ}$. Socioeconomic factors have a greater influence on the expansion of urban land, and their effects have changed over time. Population growth and economic development has played a significant role in the expansion of urban land before 2005. Subsequently, the factor of GDP and distance to the core cities of Guangzhou and Shenzhen controlled the expansion to the greatest extent. The impacts of various factors tended to become balanced during 2010-2015. The majority of the factors enhanced each other via their interactions, and the distance to the rivers always exhibited a greater enhancement when there was interaction with other factors. The spatial and temporal analysis of the urban expansion and the mechanism of the Pearl River Delta urban agglomeration could provide useful information for coastal urban planning. This study also offers new knowledge regarding the interactions between different drivers of urban land expansion.
\end{abstract}

Keywords: urban land expansion; spatial pattern; driving forces; Pearl River Delta; urban agglomeration

\section{Introduction}

Coastal areas are commonly defined as the interface or transition areas between land and sea, and they comprise diverse functions and forms with no strict spatial boundaries [1]. Coastal areas are usually characterized by flat terrain, a moderate climate, booming economy, rich resources, and convenient accessibility to marine trade and transport. The combination of these features drives coastal migration and stimulates urban expansion [2]. The majority of the world's metropolises and urban agglomerations are situated in coastal areas [3], and many of these are in large deltas. The 
rates of urban expansion in coastal areas were significantly higher than that in the hinterland from 1970 to 2000 [4]. Unprecedented urbanization has resulted in profound changes in landscape [5], biodiversity [6], biogeochemical cycles [7], and energy flow [8] at multiple spatiotemporal scales. In China, urbanization in the coastal areas also grew and expanded faster than that in the western non-coastal areas [4]. The growth rate of the coastal urban land is three times higher than the national rate and has been driven by continued economic growth and specific policies that encourage coastal city development [9]. At the same time, rapid urbanization, increasing land utilization, and pollution have also put increasingly high pressure on coastal ecosystems and natural resources [10]. Therefore, understanding the spatiotemporal patterns of the rapidly expanding coastal cities in China is important for formulating sustainable land-use and urban-planning policies.

At present, geographic information systems (GIS) combined with remote sensing (RS) and landscape indexes have been widely applied for determining the spatiotemporal dynamics of urban growth patterns [11]. RS offers consistent and frequent data from study areas with positional spatial detail [12], which can be analyzed, displayed, and described using GIS [13]. Moreover, the development of the landscape ecology can be of immense help in quantitatively describing the urban expansion patterns, and the relationship between urbanized area structure and the urbanization process using landscape metrics [14]. With the rapid development of GIS, the valuable multispectral RS data set, and various indexes in landscape ecology, the specific spatial and temporal characteristics and driving forces of urban expansion can be better understood. The combination of these three methods is effective for updating the spatial data and obtaining accurate and timely geospatial information for illustrating the change patterns of urban land expansion [15].

The Pearl River Delta is one of three "National Optimized Development Zones" in China; however, the inclusion of Hong Kong and Macao in the Greater Pearl River Delta makes it the most globally integrated of the three. Since the start of the 21st century, the spatial structure and urbanization dynamic mechanism of the Pearl River Delta urban agglomeration (PRDUA) have undergone tremendous changes. The functions of cities have become diversified, and a multi-center urban system was formed with large urban and rural population immigration [16]. As China's urbanization and industrialization process continues to accelerate, the new impetus comes mainly from the development of the urban economy, strengthening of international and national connectivity, and growth of private capital. At the same time, as a new regional unit of the country's participation in global competition and the international division of labor [17], the urban agglomeration will determine the new pattern of the global political economy in the 21st century. However, there is a lack of studies comprising the use of spatially consistent data sets with a high temporal frequency of urban conditions after the year 2000 in the Pearl River Delta. Accordingly, it is necessary to form a clearer understanding of the urban land expansion in the PRDUA.

In coastal urban ecosystems, the interactions among geographical, ecological, economic and social factors exist widely at different spatio-temporal scales [18]. The functions of one factor can be influenced by the conditions of other factors in the same urban system. It has been proven that interactions between factors can improve the accuracy of the spatial prediction of urban growth [19]. The cities in an urban agglomeration usually have frequent interactions with each other in the form of economic, social, and ecological activities. Understanding the interactions among the aforementioned factors is vital to help simulate and predict urban growth patterns more precisely, and with greater detail [20]. However, the interactions between factors are rarely studied owing to the intricate functions of the urban system. The interactions of factors that influence the development of coastal urban agglomerations require further research.

This study is aimed at exploring the spatiotemporal patterns and driving forces of coastal urban expansion based on land-use data derived from RS images. The urban agglomeration of the Pearl River Delta is taken as an example area of this study. A geographical detector is used to identify the interactions of various driving forces and their changes. In this study, we first introduce the study area and the corresponding data. The details of the method used to describe the spatiotemporal pattern 
and the approach used with respect to geographical detector are presented later. We then present the results obtained in terms of the change pattern and the driving forces, especially the interactions, of the urban-land expansion in the PRDUA over the period of 2000-2015. Finally, we discuss the mechanism by which the policies act as factors affecting the urban-land use as implicated by the results.

\section{Study Area and Data}

\subsection{Study Area}

The PRDUA is one of the world's largest and fastest growing urban regions. This massive urban agglomeration is located in Guangdong in the South China region, and consists of 15 highly interconnected cities, namely, Guangzhou, Shenzhen, Foshan, Dongguan, Zhaoqing, Shaoguan, Qingyuan, Yunfu, Huizhou, Shanwei, Heyuan, Zhuhai, Zhongshan, Jiangmen, and Yangjiang (Figure 1). Among these cities, Guangzhou is the capital of the Guangdong province and is the cultural and political center of the Pearl River Delta. Shenzhen, as a special economic zone in China, is one of the fastest-growing cities in the world. Owing to its obvious geographical advantages, the PRDUA has always been the gateway to China. The flat lands of the delta are crisscrossed by a network of tributaries and distributaries of the Pearl River. This area has a humid subtropical climate characterized by hot and humid summers and cold-to-mild winters. Around the year 2000, with the handover of Hong Kong and Macau, and with China being a member of the World Trade Organization, the PRDUA increasingly attracted the nation's capital, technology, and talents. In the 21st century, the PRDUA ushered in new opportunities for economic integration and industrial restructuring. According to the statistical data obtained from the government, the permanent population of the area has increased by $21.04 \%$ from 43.92 million in 2000 to 53.16 million in 2015, and the gross domestic product (GDP) has increased dramatically from 845.41 billion RMB in 2000 to 6823.09 billion RMB in 2015 [21,22]. The market of the PRDUA is international and active because of its proximity to Hong Kong. Its significant economic development has attracted numerous global investors. Furthermore, the industrial cities in the Pearl River Delta have been called the Factory of the World owing to the presence of industrial parks populated with factories built using foreign investments. Rapid urbanization and industrialization in the PRDUA has made it the most populated area with a high proportion of immigration. However, rapid economic and population growth have also resulted in problems, such as environmental pollution, water shortages, cropland loss, and high costs of living and housing. It is necessary to study the dynamic spatial pattern and mechanism of urban expansion in the PRDUA to obtain useful information for effective urban planning. 


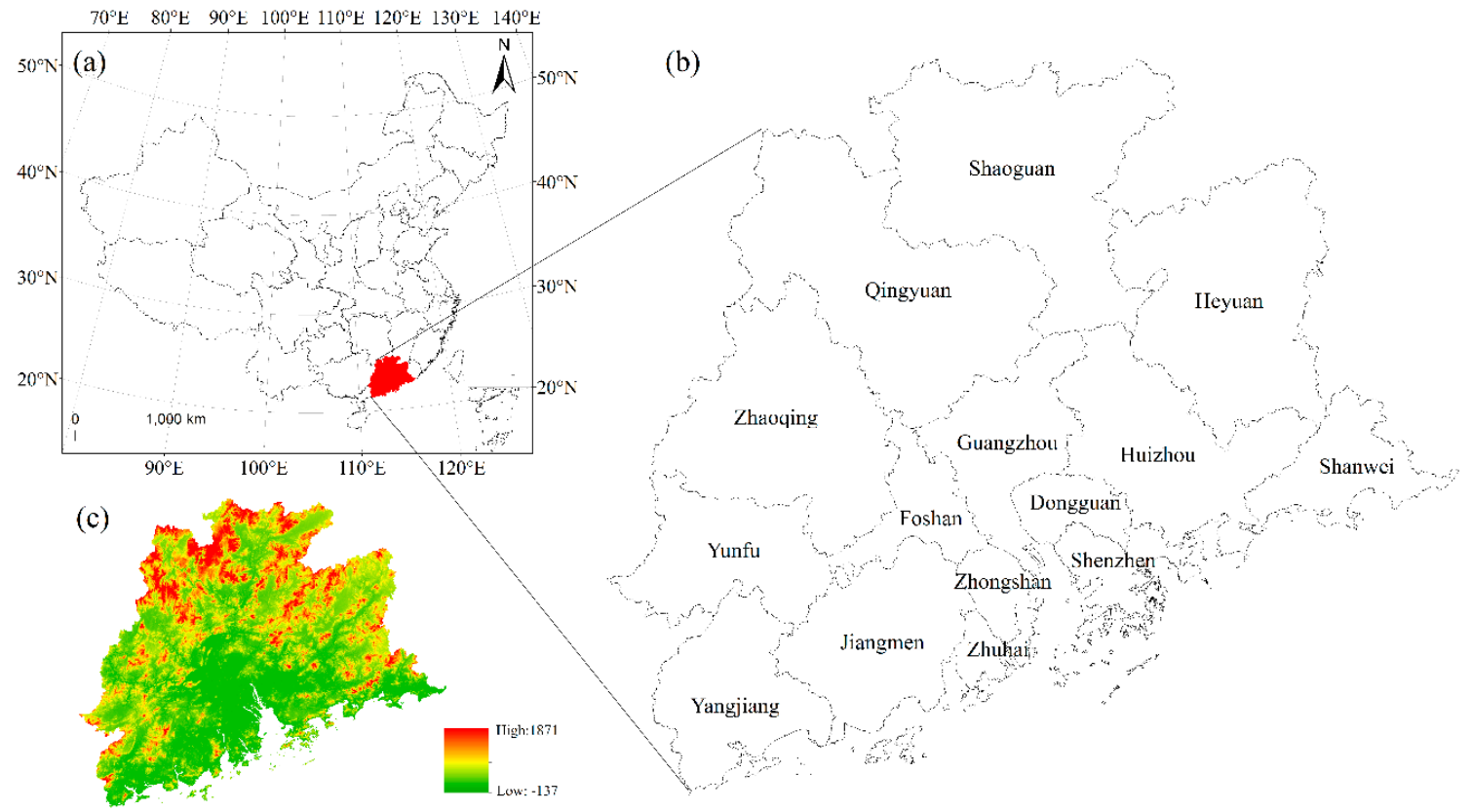

Figure 1. Location and administrative divisions of the Pearl River Delta urban agglomeration: (a) Location of the study area; (b) Administrative divisions of the study area; and (c) Topography of the study area.

\subsection{Data Source}

The data used in this study include the following: (i) land use raster data of the PRDUA in 2000, 2005, 2010, and 2015 having a spatial resolution of $100 \mathrm{~m}$ (Figure 2). The data are obtained from National Land Use/Cover Database of China. The land use types were visually interpreted from medium-resolution satellite images (Landsat MSS/TM/ETM, the China-Brazil Earth Resources Satellite and HJ-1A) and field surveys were conducted to verify the classification results [23]. The land use types are divided into six types of first-class: cropland, woodland, grassland, water bodies, built-up land, and unused land; and the built-up land contains three second-level types of urban land, rural settlement, and industry-traffic land. Urban land referred to land used for urban settlement, with a largely continuous area covered by urban construction and city facilities. (ii) The socioeconomic data of the PRDUA includes the population, GDP, secondary industry GDP, tertiary industry GDP, and total investment in fixed assets $[21,22,24,25]$. (iii) The vector data of the main roads, rivers, and coastlines are derived from the National Fundamental Geographical Information System of China. The elevation and slope data are derived from the $90 \mathrm{~m}$ elevation data of the Shuttle Radar Topography Mission. 


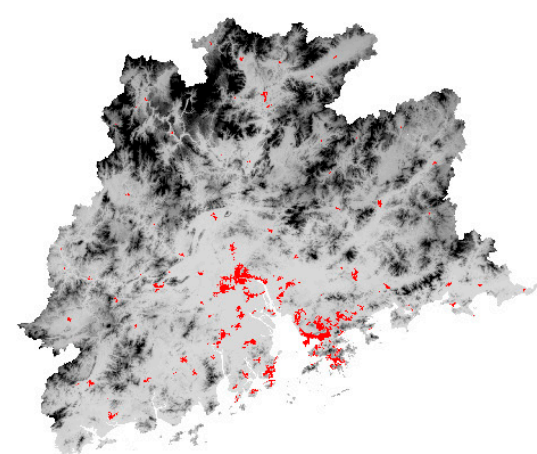

(a) 2000

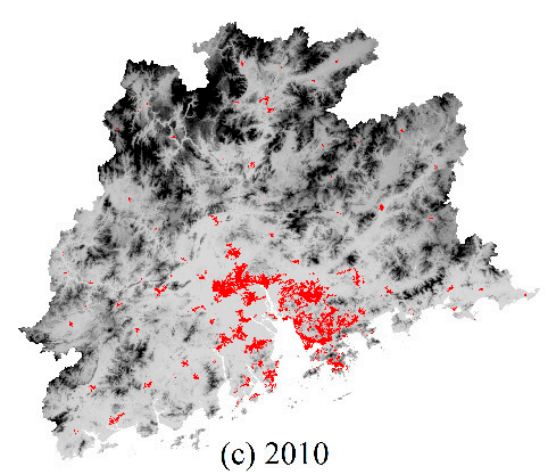

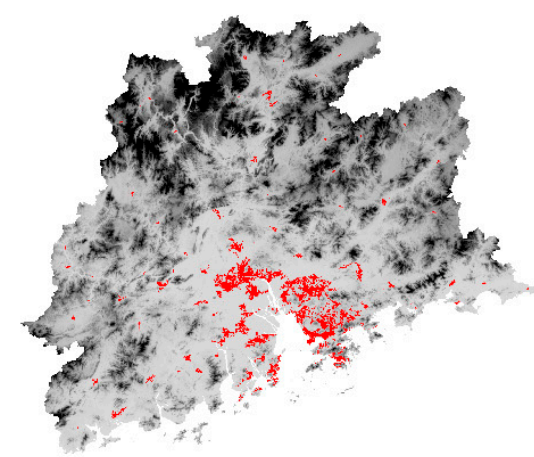

(b) 2005

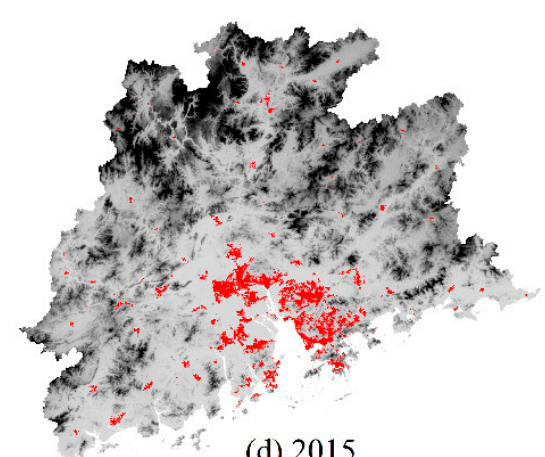

(d) 2015

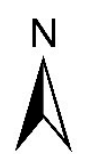

Pearl River Delta urban agglomeration

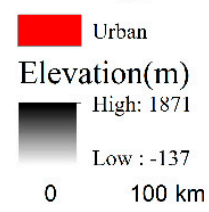

Figure 2. Spatial distribution of the urban land in the Pearl River Delta urban agglomeration from 2000 to 2015.

\section{Methods}

\subsection{Spatial Pattern Indicators}

\subsubsection{Urban-Land Expansion Intensity Index}

The urban-land expansion intensity index refers to the rate of expansion of the area of urban land within a certain period. After standardization, the speeds of urban-land expansion during different periods and in different spatial units are comparable. This index is defined as follows:

$$
U E I_{i}=\frac{U A_{i}{ }^{t+m}-U A_{i}{ }^{t}}{U A_{i}{ }^{t} \times m}
$$

where $U E I_{i}$ represents the urban land expansion intensity, $\mathrm{UA}_{i}{ }^{t+m}$ and $\mathrm{UA}_{i}{ }^{t}$ represent the urban land area in the spatial unit $i$ of $t$ and $t+m$ years, respectively, and $m$ is the number of years in the study period.

\subsubsection{Urban-Land Expansion Difference Index}

The urban-land expansion difference index represents the ratio of the urban expansion rate of the cities in the urban agglomeration to the urban expansion rate of the entire urban agglomeration over a certain period, and it makes the urban-land expansion speed of different cities comparable. The index can also indicate the coordinate development among the cities. This index is defined as follows:

$$
U E D I_{i}=\frac{\left|U A_{i}{ }^{t+m}-U A_{i}^{t}\right| \times U A^{t}}{\left|U A^{\mathrm{t}+m}-U A^{t}\right| \times U A_{i}{ }^{t}}
$$


where $U E D I_{i}$ represents the urban land expansion difference, and $U A^{t+m}$ and $U A^{t}$ represent the urban land area of the PRDUA during different time periods. Here, $U A_{i}{ }^{t+m}, U A_{i}{ }^{t}$ and $\mathrm{m}$ are the same as those in Equation (1).

\subsubsection{Fractal Dimension}

The fractal dimension is the measurement of the form of urban land. Fractal dimension changes can reflect the spatial concentration and diffusion of the urban land [26]. The more complex the shape and structure of the urban land, the greater the fractal dimension. This index is defined as follows:

$$
D_{i t}=\frac{2 \ln \left(0.25 P_{i t}\right)}{\ln \left(A_{i t}\right)}
$$

where $D_{i t}, P_{i t}$ and $A_{i t}$ represent the fractal dimension, perimeter of the urban patch, and area of the urban patch, respectively, of the $i$ th city in year $t$. The fractal dimension has a value range of $1-2$. The complexity of the urban form is positively correlated with the value of the fractal dimension. When the value of the fractal dimension is greater than 1.5 , the form of the urban land is complicated. In contrast, and the urban form is relatively simple [27].

\subsection{Driving Force Analysis-Geographical Detector}

A geographical detector comprises a set of statistical methods that are used to identify the spatial differentiation and reveal the driving mechanism behind geographical phenomena [28]. This method includes four detectors, namely: factor, risk, ecological, and interaction detectors. In this study, mainly the factor, risk, and interaction detectors are used to analyze the relative influence of the various factors in the urban expansion of the PRDUA, how each factor influences the expansion, and the interactions between the different factors.

\section{(1) Factor Detector}

The factor detector can quantitatively represent the relative importance of each possible factor. The power determinant $(p)$ is defined as the difference of one and the ratio of the accumulated variance of the urban land growth area in the sub-regions of a factor to that over the entire study area [29]:

$$
p=1-\frac{\sum_{i=1}^{N} n_{i} \sigma_{i}^{2}}{n \sigma^{2}}
$$

where $N$ is the number of strata of the potential factor, and $n_{i}$ and $n$ are the number of grid elements of the strata $i$ and the whole region, respectively. $\sigma_{i}{ }^{2}$ and $\sigma^{2}$ are the variances of the urban-land area in the strata $i$ and the whole region, respectively. The value range of $p$ is $[0,1]$, and the greater the value of $p$, the greater the influence of the factor is.

\section{(2) Risk Detector}

In the case of the risk detector, the $t$-test is used to perform a comparison to determine whether the difference between the sub-regions divided by the potential factor is significant. In this study, the average expanded urban area of the grid cells in a sub-region $D i$ is calculated as follows [20]:

$$
U_{\mathrm{d}}=\frac{1}{n_{D i}} \sum_{1}^{n_{D i}} y_{D i}
$$

where $y_{D i}$ denotes the urban expanded area of a grid in a strata $D i$, and $n_{D i}$ denotes the number of grids in the strata. Using the $U_{\mathrm{d}}$ values, a comparison of the effects of different levels of a factor can be conveniently performed. The greater the value of $U_{\mathrm{d}}$, the more rapid the urban-land expansion is. 
(3) Interaction Detector

The interaction detector identifies how two different factors interact to exert an impact on the spatial expansion of the urban agglomeration. The interaction detector quantifies the interaction of the two possible influence factors as follows:

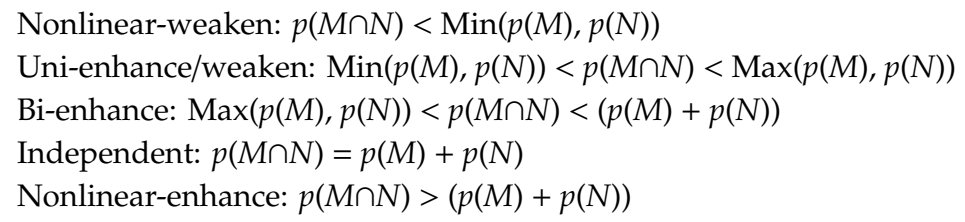

where the symbol " $\cap$ " denotes the interaction between factors $M$ and $N$. In the Esri ArcGIS platform, the overlay of two influence factor (such as $M$ and $N$ ) layers can be realized. When layer $O$ is formed, the $p$ values of $M, N$, and $O$ are respectively input into the above formula to determine whether the two factors have interactions, and if the interactions are enhanced or weakened.

\subsection{Driving Factors Selection}

The factors affecting the expansion of urban land are diverse and the mechanism of land use change is complex. Based on a review of the extant research, the driving forces for urban-land expansion comprise three categories, namely physical, socioeconomic, and policy factors [20]. These factors interact and drive the expansion of urban land in urban agglomerations. The physical factors determine the background conditions for regional urban-land expansion [30,31]. The mountains and hills are sparsely distributed in the northern, eastern, and western parts of the PRDUA, which may restrict the expansion of the urban land (Figure 1c). As a coastal urban agglomeration, the sea could serve as a natural transportation hub to the outside areas, which could influence urban development. The Pearl River Delta is formed by three major rivers, including the Xi Jiang (West River), Bei Jiang (North River), and Dong Jiang (East River). Therefore, the terrain, distance to the sea, and river distribution may determine the potential, intensity, direction, and scale of the urban-land expansion. Socioeconomic factors are also vital factors affecting urbanization [32-34]. The rapidly growing population, increasing GDP, and investment in infrastructure all directly stimulate urban expansion. At the same time, as an effective means for the government to regulate urban development, policy factors have played an important role in urban planning. However, it is often difficult to quantify policy factors. In this study, the impact of the policy factors is revealed using physical and socioeconomic factors as geographic proxies. The so-called geographic proxies refer to factors that can be spatially represented in the real world owing to the determining factors behind the geographical phenomena [35]. The policy factors always interact with physical and socioeconomic factors, and thus the impact of the policy factors is reflected in the spatial pattern of land-use change and changes in the physical and socioeconomic factors. For example, the formulation of a policy may result in population gathering and economic growth, which would stimulate the expansion of urban land. Therefore, the effects of the policy are reflected by socioeconomic indicators such as population growth and GDP change. Based on the above considerations, in this study, 10 physical and socioeconomic factors are selected as the driving factors for urban-land expansion in the PRDUA (Table 1). Furthermore, these factors are introduced as geographical proxy factors for the policy factors in later analysis. 
Table 1. Driving factors of urban land expansion in the Pearl River Delta urban agglomeration.

\begin{tabular}{cccc}
\hline Category & Variable & Abbreviation & Unit \\
\hline \multirow{3}{*}{ Physical factors } & Elevation & ELE & $\mathrm{m}$ \\
& Slope & SLP & $\mathrm{km}^{-}$ \\
& Distance to rivers & D_RV & $\mathrm{km}$ \\
\hline \multirow{3}{*}{ Docistance to coastline } & D_CL & P_POP & thousand persons \\
& Permanent population & billion RMB \\
& Gross domestic product & GDP & \% \\
& Proportion of secondary and tertiary & ST_GDP & billion RMB \\
& industries in GDP & T_FAI & $\mathrm{km}$ \\
& Total investment in fixed assets & Distance to main roads & $\mathrm{km}$ \\
\hline
\end{tabular}

\section{Results}

\subsection{Spatial Pattern of Urban Land Expansion}

The urban land expansion intensity indexes for the three time periods, 2000-2005, 2005-2010, and 2010-2015, and the entire time period are presented in Table 2. The results indicate that although the area of the urban land in the PRDUA continued to expand, its expansion intensity demonstrated a downward trend. The intensity of the urban-land expansion peaked in 2000-2005, and those of the majority of the cities were consistent with that of the whole area. The decreasing trend of the intensity of urban-land expansion may have been influenced by the "National Principal Function Zoning Plan" in 2010, which emphasized the optimization of construction-land expansion mode based on different function divisions. In 2005-2010 and 2010-2015, the difference in the intensity of expansion among the cities significantly reduced, thereby reflecting the coordinate development within the urban agglomerations. This change may demonstrate that the spatial structure of the PRDUA changed from two single-center structures in Guangzhou and Shenzhen to a multi-centered structure (Figure 2).

Table 2. Urban-land expansion intensity in Pearl River Delta urban agglomeration.

\begin{tabular}{ccccc}
\hline City & $\mathbf{2 0 0 0 - 2 0 0 5}$ & $\mathbf{2 0 0 5 - 2 0 1 0}$ & $\mathbf{2 0 1 0 - 2 0 1 5}$ & $\mathbf{2 0 0 0 - 2 0 1 5}$ \\
\hline Guangzhou & 0.141 & 0.036 & 0.019 & 0.080 \\
Shenzhen & 0.040 & 0.026 & 0.015 & 0.030 \\
Foshan & 0.057 & 0.015 & 0.001 & 0.026 \\
Dongguan & 0.037 & 0.015 & 0.011 & 0.023 \\
Zhuhai & 0.187 & 0.046 & 0.014 & 0.103 \\
Zhongshan & 0.031 & 0.048 & 0.028 & 0.042 \\
Zhaoqing & 0.023 & 0.022 & 0.045 & 0.034 \\
Yunfu & 0.086 & 0.075 & 0.023 & 0.079 \\
Yangjiang & 0.039 & 0.010 & 0.021 & 0.026 \\
Shaoguan & 0.065 & 0.018 & 0.016 & 0.037 \\
Shanwei & 0.068 & 0.022 & 0.075 & 0.069 \\
Qingyuan & 0.155 & 0.011 & 0.038 & 0.081 \\
Huizhou & 1.304 & 0.044 & 0.008 & 0.571 \\
Heyuan & 0.415 & 0.025 & 0.026 & 0.193 \\
Jiangmen & 0.087 & 0.027 & 0.142 & 0.119 \\
PRDUA & 0.153 & 0.032 & 0.016 & 0.081 \\
\hline
\end{tabular}

Figure 3 shows the spatial pattern of the urban-land expansion difference of each city, and the five categories were defined as slow development, relatively slow development, medium-speed development, relatively rapid development, and rapid development according to Jenk's natural breaks. The speed of urban-land expansion varied between cities over different time periods. From 2000 to 2005, the cities of Dongguan, Zhongshan, Guangzhou, Foshan, and Qingyuan were developing rapidly 
(Figure 3a). From 2005 to 2010, Guangzhou, Foshan, and Dongguan had a high expansion speed, which stimulated Huizhou and Jiangmen to become the new rapid-expansion zones (Figure 3b). From 2010 to 2015, the expansion speed of the southwestern part of the PRDUA was significantly higher than that of the central and eastern regions (Figure 3c). This phenomenon may have been influenced by the construction of Hong Kong-Zhuhai-Macao Bridge at the end of 2009, which strengthened the effect of Zhuhai causing an improvement in the development of the west of the Pearl River Estuary during this period. Overall, the expansion of urban land in the PRDUA was mainly concentrated in the central and southern regions, and the index showed a decreasing tendency as the distance to the Pearl River Estuary increased (Figure 3d).

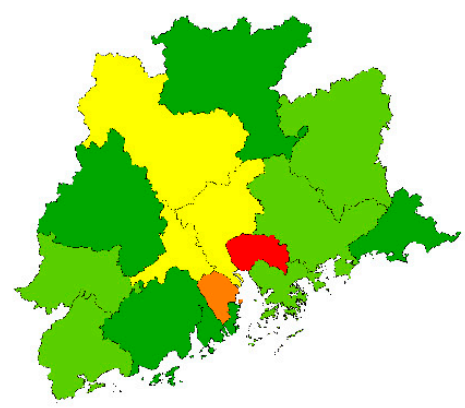

(a) 2000-2005

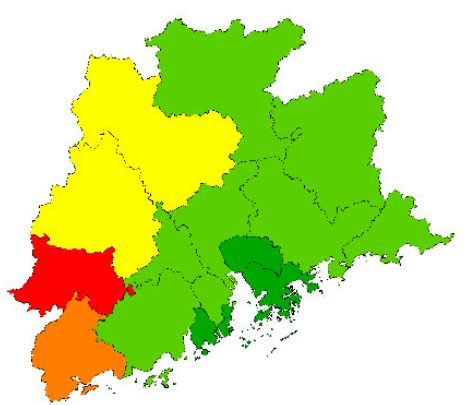

(c) 2010-2015

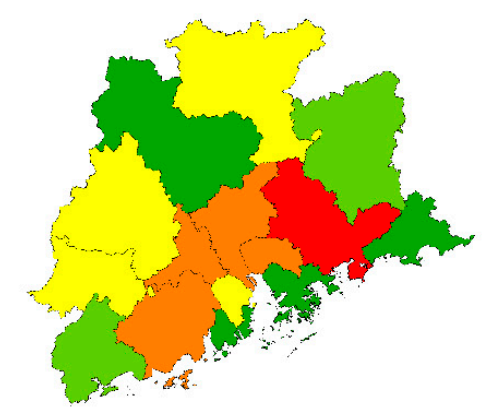

(b) $2005-2010$

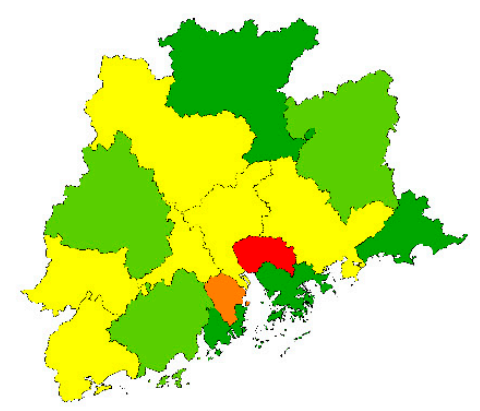

(d) 2000-2015

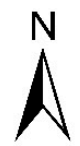

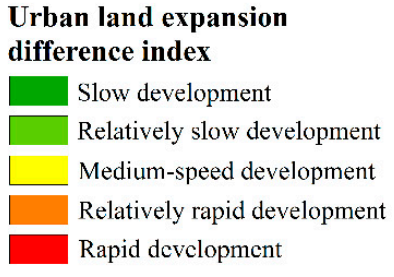

$0 \quad 100 \mathrm{~km}$

Figure 3. Spatial characteristics of the urban-land expansion difference index in the Pearl River Delta urban agglomeration.

During 2000-2015, the fractal dimensions of Shenzhen, Dongguan, and Foshan were significantly greater than those of other cities, which indicated that the urban form was more complicated in these cities. The maximum fractal dimension of all the cities during this period did not exceed 1.3, thus revealing that the urban form within the PRDUA was relatively simple and regular. During the study period, the fractal dimension of Guangzhou, Shenzhen, Zhaoqing, Shaoguan, Qingyuan, and Heyuan increased continuously, thus demonstrating that the shape of the cities became increasingly complicated, which was due to the increase in human interference activities. In contrast, the fractal dimension of the other cities first increased and then decreased, which may indicate that the urban development experienced a process of disorderly development followed by planned development during this period. From 2000 to 2015, the fractal dimensions of Shenzhen and Zhongshan changed the most, while the fractal dimension of Zhuhai changed the least. This phenomenon indicated that the shape of the Shenzhen and Zhongshan cities changed drastically in those 15 years, while the urban form of Zhuhai remained relatively stable (Table 3). 
Table 3. Fractal dimension index of cities in the Pearl River Delta urban agglomeration.

\begin{tabular}{cccccc}
\hline City & $\mathbf{2 0 0 0}$ & $\mathbf{2 0 0 5}$ & $\mathbf{2 0 1 0}$ & $\mathbf{2 0 1 5}$ & Changes \\
\hline Guangzhou & 1.1687 & 1.2002 & 1.2057 & 1.2070 & 0.0383 \\
Shenzhen & 1.1926 & 1.2282 & 1.2328 & 1.2464 & 0.0538 \\
Foshan & 1.2005 & 1.2068 & 1.1837 & 1.1862 & -0.0143 \\
Dongguan & 1.2131 & 1.2444 & 1.2392 & 1.2417 & 0.0286 \\
Zhuhai & 1.1643 & 1.1672 & 1.1701 & 1.1660 & 0.0017 \\
Zhongshan & 1.1518 & 1.2209 & 1.2098 & 1.2056 & 0.0538 \\
Zhaoqing & 1.1436 & 1.1485 & 1.1525 & 1.1595 & 0.0159 \\
Yunfu & 1.1491 & 1.1561 & 1.1539 & 1.1762 & 0.0271 \\
Yangjiang & 1.1879 & 1.2042 & 1.2062 & 1.2060 & 0.0181 \\
Shaoguan & 1.1204 & 1.1366 & 1.1471 & 1.1480 & 0.0276 \\
Shanwei & 1.1029 & 1.1330 & 1.1392 & 1.1387 & 0.0358 \\
Qingyuan & 1.1118 & 1.1404 & 1.1421 & 1.1433 & 0.0315 \\
Huizhou & 1.1369 & 1.1890 & 1.1757 & 1.1830 & 0.0461 \\
Heyuan & 1.1766 & 1.2118 & 1.2133 & 1.2159 & 0.0393 \\
Jiangmen & 1.1878 & 1.1980 & 1.2058 & 1.2042 & 0.0164 \\
\hline
\end{tabular}

\subsection{Results of Driving-Forces Analysis}

\subsubsection{Factor and Risk Detector}

The factor detector is a measure of the relative importance of various factors to the expansion of the urban land. Between 2000 and 2005, socioeconomic factors had a significant effect on urban-land expansion. The increase in population had the greatest influence, followed by those of fixed asset investments and GDP. Between 2005 and 2010, the GDP still played as an important factor influencing the urban-land expansion. The distance to Guangzhou and Shenzhen became the second important driving force, thus indicating that the two cities played a significant role in the urban agglomeration during this period. However, the influence of distance to Guangzhou and Shenzhen decreased significantly between 2010 and 2015. In contrast, physical factors such as elevation, slope, and distance to the rivers had a relatively low effect on the urban-land expansion over the whole period. The distance to the coastline was the most influential physical factor during the first period and its influence decreased after 2005. Overall, the socioeconomic indicators, such as the influence of population, investment in fixed assets, GDP, and the distance to the core cities of the urban agglomeration had a higher impact at first, but the impact of the socioeconomic and physical factors gradually became even in 2010-2015 (Table 4).

Table 4. The $p$ values of the driving factors from 2000 to 2015 (Acronyms are defined in Table 1).

\begin{tabular}{cccc}
\hline Driving Factor & $\mathbf{2 0 0 0 - 2 0 0 5}$ & $\mathbf{2 0 0 5 - 2 0 1 0}$ & $\mathbf{2 0 1 0 - 2 0 1 5}$ \\
\hline P_POP & $44.83 \%$ & $10.58 \%$ & $2.39 \%$ \\
T_FAI & $32.55 \%$ & $8.51 \%$ & $2.63 \%$ \\
GDP & $29.94 \%$ & $27.42 \%$ & $5.40 \%$ \\
D_GS & $22.14 \%$ & $25.18 \%$ & $6.93 \%$ \\
D_CL & $9.04 \%$ & $3.57 \%$ & $3.31 \%$ \\
ST_GDP & $6.16 \%$ & $19.52 \%$ & $5.67 \%$ \\
ELE & $5.21 \%$ & $15.28 \%$ & $5.26 \%$ \\
SLP & $4.83 \%$ & $16.95 \%$ & $4.75 \%$ \\
D_RV & $3.96 \%$ & $7.47 \%$ & $3.95 \%$ \\
D_RD & $2.96 \%$ & $4.98 \%$ & $2.25 \%$ \\
\hline
\end{tabular}

The risk detector presented a comparison of the mean values of the urban-land expansion in different sub-regions to determine where the urban-land expansion was severe. The expanded area of the urban land was basically positive in relation to the population growth during 2000-2015 (Figure $4 \mathrm{a}-\mathrm{c}$ ). The urban-land expansion rate was significantly greater than the population growth 
rate. During the study period, the area of the urban land increased by $121.6 \%$, and the population increased by $21.0 \%$. The growth rate of the urban-land area was 5.79 times that of the population, thus further demonstrating the uncoordinated development between the urban land and population in coastal areas $[4,36]$.
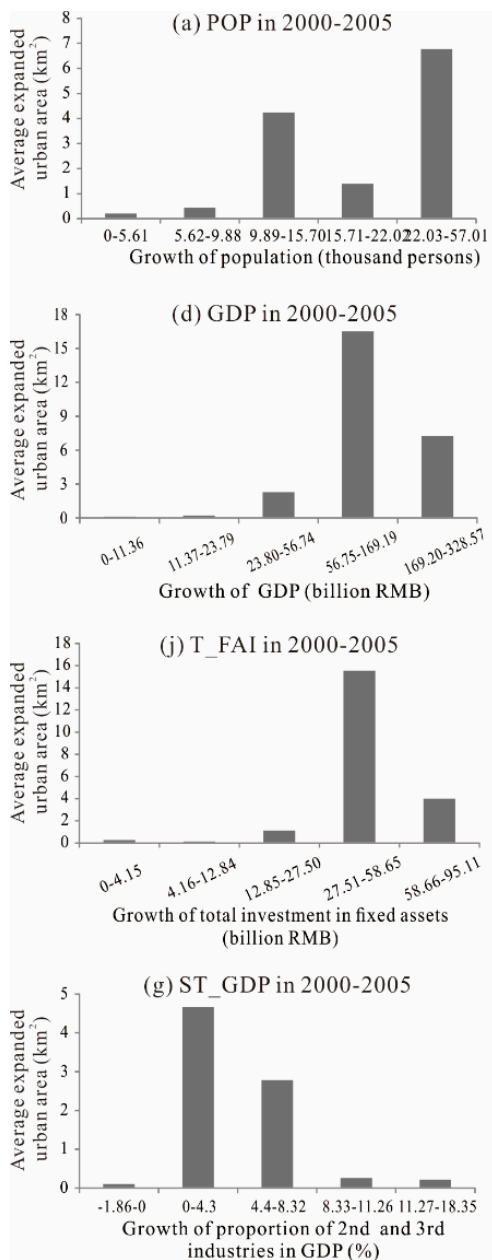
growth of population, (d-1) growth of GDP, $(\mathbf{g}-\mathbf{i})$ growth of investment in fixed assets, and $(\mathbf{j}-\mathbf{1})$ growth of proportion of 2nd and 3rd industries in GDP. Acronyms are defined in Table 1).

Similarly, the greater the increase in GDP and total investment in fixed assets, the more intensive the urban-land expansion was (Figure 4d-i). During the study period, the GDP growth in the fourth sub-region was the most dramatic. The urban statistics showed that Dongguan and Foshan were both in this sub-region in three periods, and they were the two cities with the highest urbanization rate.

During the two initial periods, urban-land expansion was dynamic where the increase of the proportion of secondary and tertiary industries in GDP was small. This may have been because land resources were more important for the initial development of the secondary and tertiary industries. The demand for land in the stage during which the secondary and tertiary industries increased at a high speed was reduced because the emphasis was focused more on the quality development. During 2010-2015, the proportion of secondary and tertiary industries in GDP increased at a slower rate than in the former two periods. The urban area expanded the most where the increased value of the secondary and tertiary industries in GDP was $0.07 \%-0.53 \%$, thus indicating that the optimization of the industrial structure promoted the expansion of urban land (Figure $4 \mathrm{j}-1)$. 
The factors of regional slope and elevation had similar effects on urbanization. In areas with elevations below $120 \mathrm{~m}$ and a slope less than $5^{\circ}$, the average expanded area of each grid reached a maximum value. This is because urban expansion tended to occur at the least cost in areas where the terrain was low and flat. Furthermore, the population also tended to gather in flat and low coastal areas, which may have interactively enhanced the urban-land expansion (Figure 5a,b).
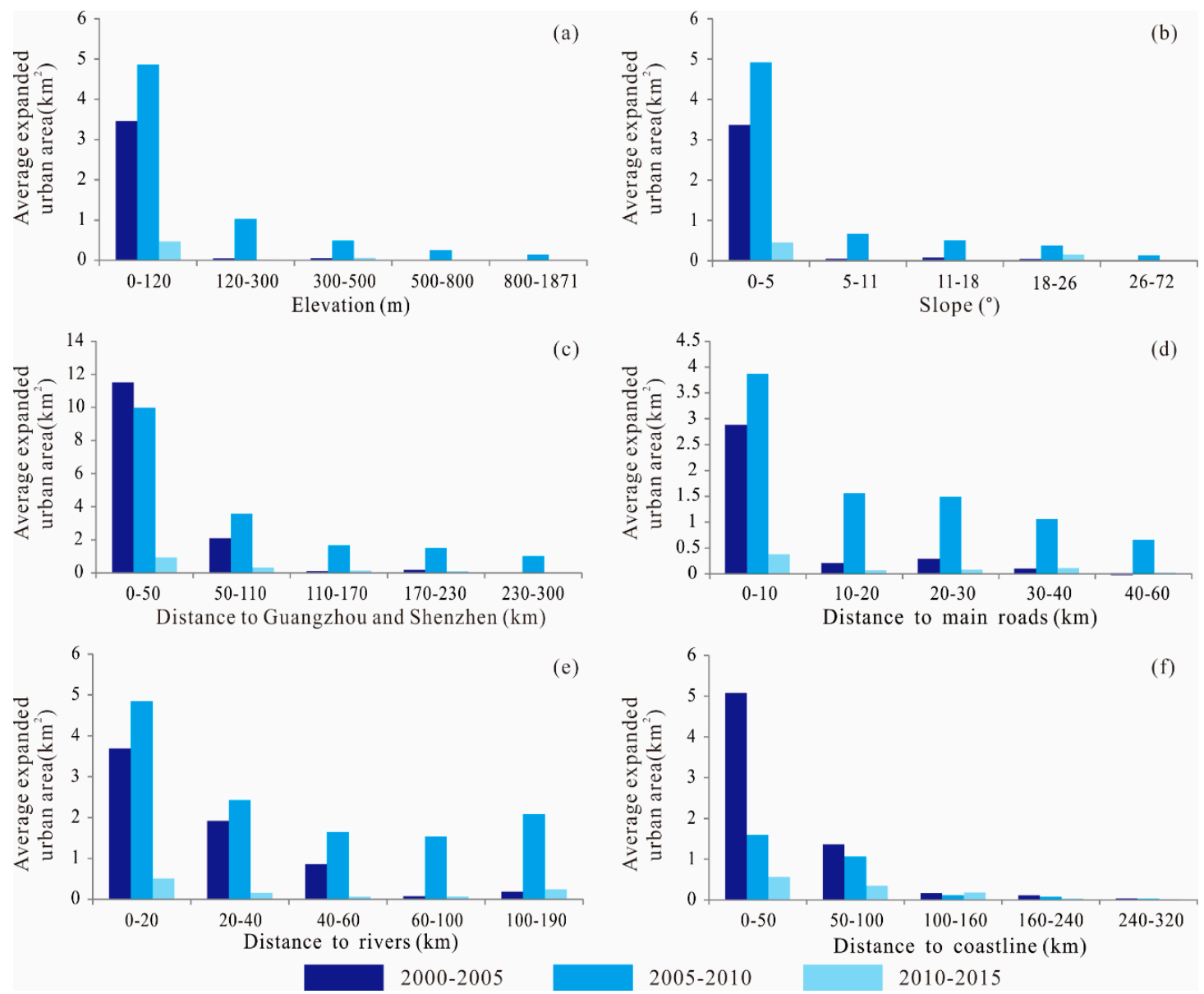

Figure 5. Average expanded urban area in different sub-regions from 2000 to 2015 (Factors of (a) Elevation, (b) Slope, (c) Distance to Guangzhou and Shenzhen, (d) Distance to main roads,

(e) Distance to rivers and (f) Distance to coastline).

The distance to the two major cities of Shenzhen and Guangzhou had an apparent effect on the urban-land expansion. As the distance increased, the expansion intensity of the urban land decreased significantly during the first two periods. This non-linear negative correlation was mitigated in 2010-2015. This phenomenon reflected the core driving effects of the major cities on urbanization in the urban agglomeration during the initial expansion of the city. However, this effect tended to decrease when the urban agglomeration developed into a new stage with greater emphasis on quality and structure (Figure $5 \mathrm{c}$ ).

Similarly, the impact of roads, rivers, and the coastline also showed a negative relationship with the urban-land expansion. The closer to the main roads, rivers, and coastline, the more intense the urban-land expansion was. The urban-land expansion was severe in regions within $10 \mathrm{~km}$ from main roads, $20 \mathrm{~km}$ from rivers, and $50 \mathrm{~km}$ from the coastline in the PRDUA (Figure $5 \mathrm{~d}-\mathrm{f}$ ). This was because the construction of roads could improve the accessibility of the local areas, and rivers could serve as tourist attractions and provide convenient water and land connections. The distance to the coastline has 
a close relationship with the terrain and port transportation, and thus it showed a negative relationship with the urban land expansion.

\subsubsection{Interaction Detector}

There are 55 pairs of interactions between 10 influencing factors. These interactions were analyzed using three categories: pairs of socioeconomic factors, pairs of physical factors, and pairs of socioeconomic and physical factors. The results showed that if any two factors were superimposed, the explanatory power of urban land expansion was enhanced in the PRDUA.

We found that, between 2000 and 2005, the average interaction between pairs of socioeconomic factors was the strongest, whereas that between pairs of physical factors was the weakest (Table 5). For example, the top four interactions between pairs of socioeconomic factors included the population interacting with the following factors: distance to Guangzhou and Shenzhen (0.5201), total investment in fixed assets (0.5022), GDP (0.4988), and the proportion of secondary and tertiary industries in GDP (0.4983). At the same time, the greatest interaction between pairs of socioeconomic and physical factors was the pair of the population and the distance to coastline interacting (0.4970). In addition, the interaction between the distance to the coastline and the distance to rivers was the strongest in comparison the other pairs of physical factors in the periods.

Table 5. Interactions between the driving factors in 2000-2005 (Acronyms are defined in Table 1).

\begin{tabular}{|c|c|c|c|c|c|c|c|c|c|c|}
\hline Factors & P_POP & GDP & ST_GDP & T_FAI & D_GS & D_RD & ELE & SLP & D_RV & D_CL \\
\hline P_POP & 0.4483 & & & & & & & & & \\
\hline GDP & 0.4988 & 0.2994 & & & & & & & & \\
\hline ST_GDP & 0.4983 & $0.4910 *$ & 0.0616 & & & & & & & \\
\hline T_FAI & 0.5022 & 0.3332 & $0.5076 *$ & 0.3255 & & & & & & \\
\hline D_GS & 0.5201 & 0.3348 & $0.2869 *$ & 0.3424 & 0.2214 & & & & & \\
\hline D_RD & 0.4551 & 0.3054 & $0.0952 *$ & 0.3401 & 0.2338 & 0.0296 & & & & \\
\hline ELE & 0.4660 & 0.3169 & 0.1091 & 0.3489 & 0.2351 & 0.0823 & 0.0521 & & & \\
\hline SLP & 0.4707 & 0.3229 & 0.0990 & 0.3733 & 0.2489 & 0.0754 & 0.0672 & 0.0483 & & \\
\hline D_RV & 0.4646 & 0.3144 & $0.1219 *$ & $0.3830 *$ & 0.2540 & 0.0699 & $0.0968^{*}$ & 0.0974 * & 0.0396 & \\
\hline D_CL & 0.4970 & 0.4508 & 0.1243 & 0.4023 & 0.2842 & $0.1689 *$ & 0.1139 & 0.1230 & $0.2308^{*}$ & 0.0904 \\
\hline
\end{tabular}

The symbol "** denotes the nonlinear enhancement of two factors. The average interaction of each category: pairs of socioeconomic factors: 0.3830 , pairs of physical factors: 0.0960 , and pairs of socioeconomic and physical factors: 0.2785 .

In 2005-2010, the interactions of the pairs of socioeconomic factors and pairs of physical factors still occupied the strongest and weakest positions, respectively, but the average interaction between the pairs of physical factors was significantly enhanced as compared to that of the previous period (Table 6). The top three interactions between pairs of socioeconomic factors comprised that of the distance to Guangzhou and Shenzhen with the population (0.4042), proportion of secondary and tertiary industries in GDP (0.3468), and GDP (0.3326). In addition, three of the four greatest interactions between the socioeconomic factors and physical factors were observed between the distance to rivers and the following factors: GDP (0.3684), distance to Guangzhou and Shenzhen (0.3602), and secondary and tertiary industries in GDP (0.3549). 
Table 6. Interactions between the driving factors in 2005-2010 (Acronyms are defined in Table 1).

\begin{tabular}{|c|c|c|c|c|c|c|c|c|c|c|}
\hline Factors & P_POP & GDP & ST_GDP & T_FAI & D_GS & D_RD & ELE & SLP & D_RV & D_CL \\
\hline P_POP & 0.1058 & & & & & & & & & \\
\hline GDP & 0.3150 & 0.2742 & & & & & & & & \\
\hline ST_GDP & 0.3270 * & 0.3104 & 0.1952 & & & & & & & \\
\hline T_FAI & 0.1469 & 0.2965 & $0.3244 *$ & 0.0851 & & & & & & \\
\hline D_GS & $0.4042 *$ & 0.3326 & 0.3468 & 0.2645 & 0.2518 & & & & & \\
\hline D_RD & 0.1475 & 0.2873 & 0.2262 & 0.1273 & 0.2755 & 0.0498 & & & & \\
\hline ELE & 0.2163 & 0.3438 & 0.2535 & 0.2156 & 0.3086 & 0.1829 & 0.1528 & & & \\
\hline SLP & 0.2321 & 0.3699 & 0.2880 & 0.2327 & 0.3522 & 0.1929 & 0.2020 & 0.1695 & & \\
\hline D_RV & $0.1841 *$ & 0.3684 * & $0.3549 *$ & $0.2068 *$ & $0.3602 *$ & 0.1267 * & 0.2138 & 0.2369 & 0.0747 & \\
\hline D_CL & 0.1216 & 0.2912 & 0.2123 & $0.1531 *$ & 0.2777 & 0.1065 * & 0.1703 & 0.1962 & 0.1984 * & 0.0358 \\
\hline
\end{tabular}

The symbol "** denotes the nonlinear enhancement of two factors. The average interaction of each category: pairs of socioeconomic factors: 0.2755 , pairs of physical factors: 0.1650 , and pairs of socioeconomic and physical factors: 0.2480 .

In 2010-2015, the average interaction between socioeconomic factors and physical factors was stronger than that between the other two types of interactions (Table 7). The strongest three interactions between pairs of socioeconomic and physical factors were observed between the distance to Guangzhou and Shenzhen and the distance to rivers (0.1125), GDP and the distance to rivers (0.1066), and the distance to Guangzhou and Shenzhen and the slope (0.0996). The strongest interaction between the pairs of socioeconomic factors was between the distance to Guangzhou and Shenzhen and the total investment in fixed assets (0.1095).

Table 7. Interactions between the driving factors in 2010-2015 (Acronyms are defined in Table 1).

\begin{tabular}{|c|c|c|c|c|c|c|c|c|c|c|}
\hline Factor & P_POP & GDP & ST_GDP & T_FAI & D_GS & D_RD & ELE & SLP & D_RV & D_CL \\
\hline P_POP & 0.0239 & & & & & & & & & \\
\hline GDP & 0.0887 * & 0.0540 & & & & & & & & \\
\hline ST_GDP & 0.0753 & 0.1004 & 0.0567 & & & & & & & \\
\hline T_FAI & 0.0415 & 0.0854 * & 0.0680 & 0.0263 & & & & & & \\
\hline D_GS & 0.1078 * & 0.0838 & 0.0988 & 0.1095 * & 0.0693 & & & & & \\
\hline D_RD & 0.0438 & 0.0710 & 0.0746 & 0.0495 & 0.0859 & 0.0225 & & & & \\
\hline$\overline{E L E}$ & 0.0686 & 0.0815 & 0.0870 & 0.0746 & 0.0922 & 0.0722 & 0.0526 & & & \\
\hline SLP & 0.0770 * & 0.0839 & 0.0946 & 0.0675 & 0.0996 & 0.0645 & 0.0688 & 0.0475 & & \\
\hline D_RV & $0.0776^{*}$ & $0.1066^{*}$ & 0.0993 * & 0.0797 * & 0.1125 * & 0.0639 * & 0.0894 & 0.0894 * & 0.0395 & \\
\hline D_CL & $0.0702 *$ & 0.0777 & 0.0833 & 0.0669 * & 0.0954 & 0.0760 * & 0.0615 & 0.0676 & $0.0967 *$ & 0.0331 \\
\hline
\end{tabular}

The symbol "*" denotes the nonlinear enhancement of two factors. The average interaction of each category: pairs of socioeconomic factors: 0.0789 , pairs of physical factors: 0.0646 , and pairs of socioeconomic and physical factors: 0.1085 .

The nonlinear enhancement, as the strongest type of enhancement, should be further analyzed. During 2000-2005, nonlinear enhancement was observed in the interactions related to the factors of the proportion of secondary and tertiary industries in GDP, distance to rivers, and distance to coastline, thus demonstrating that the interactions between these factors significantly promoted the expansion of urban land. From 2005 to 2015, the distance to river and the majority of the socioeconomic factors interacted nonlinearly, which indicated that the existence of rivers could act as a catalyst for urban expansion. It also showed that the number of pairs demonstrating nonlinear enhancement increased significantly during the study period, which indicated closer and more complicated interactions within the urban agglomeration (Tables 5-7).

\section{Discussion: Implications of Political Effects}

Policies and urban planning play a vital role in the expansion of urban land in the PRDUA, and their impact is reflected in the spatial pattern of urban land and changes in the driving factors. Based on the above results, several policies and major events were found to exert a significant impact on the expansion of urban land in the PRDUA.

The relatively high impact of the distance to Guangzhou and Shenzhen before 2010 proved that the spatial distribution of urban-land expansion was highly consistent with the distance to the core 
cities. This indicated that Guangzhou and Shenzhen are the economic cores of the area that stimulate regional development. However, the influence of the distance to Guangzhou and Shenzhen decreased during 2010-2015. This phenomenon indicated the effects of policy have promoted the spatial pattern of the PRDUA from the dual-center pattern to a relative integrated pattern. During the study period, the local government promoted three regional plans to manage and guide the urban development of the Pearl River Delta: Pearl River Delta Urban Cluster Coordinated Development Plan (2004-2020), The Outline of the Plan for the Reform and Development of the Pearl River Delta (2008-2020), and The Pearl River Delta Urban-Rural Integration Planning (2009-2020). In these three plans, the core ideas were to form a multi-center pattern of the region aimed at balancing the development of the eastern, western, and central areas, and forming a structure of large, middle, and small cites in the urban agglomeration. In these plans, the "Guangzhou-Foshan-Zhaoqing" was proposed to be considered as the central metropolitan area, "Shenzhen-Dongguan-Huizhou" as the eastern metropolitan area, and "Zhuhai-Zhongshan-Jiangmen" as the western metropolitan area. Guangzhou, Shenzhen, and Zhuhai were considered as the core cities of each metropolitan area. However, according to the urban-land expansion process observed in this study, the eastern, western, and central metropolitan areas in the PRDUA still developed in an unbalanced manner (Figure 6). In the central metropolitan area, Guangzhou and Foshan were relatively integrated, but Zhaoqing was lagging. In the eastern metropolitan area, Shenzhen and Dongguan were more developed with the development in Huizhou being marginal. In comparison, the western metropolitan area was least developed, and Zhuhai was less developed as compared with Guangzhou and Shenzhen. Overall, the decreasing influence of the distance to the Guangzhou and Shenzhen reflected the effect of the policies aimed at coordinating the development of the region, although the effects of the policies tended to exhibit a lag of approximately 5-10 years. In terms of urban-land development, more time may be required to realize multi-center integrated development in the PRDUA.
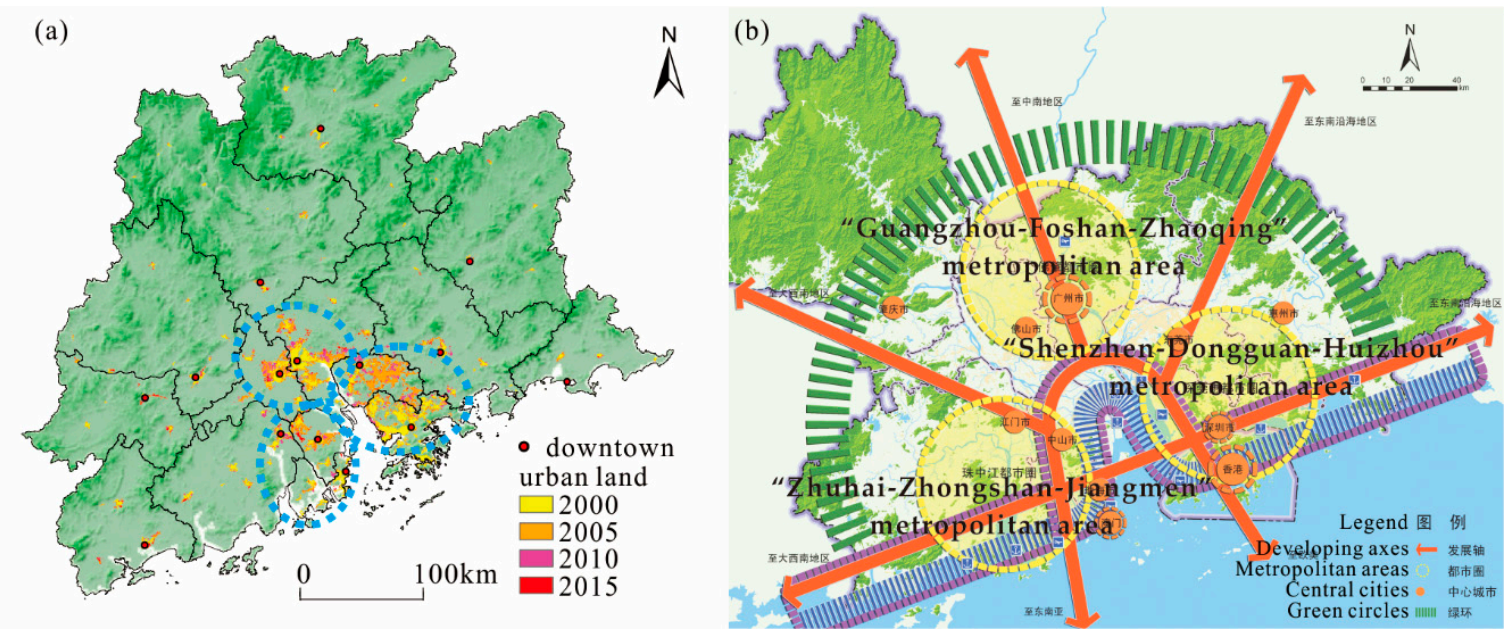

Figure 6. Comparison of (a) urban land expansion in 2000-2015 in the Pearl River Delta urban agglomeration with (b) the plan of The Pearl River Delta Urban-Rural Integration Planning (2009-2020).

The environmental protection policy also played an important role in the development of urban land in the PRDUA. The topographic factors were influential, and the expansion intensity was relatively low in higher and steeper districts in the north of the PRDUA (Table 4 and Figure 5). According to the division of "Guangdong Principal Functional Zoning Plan (2012-2020)," Shaoguan, Heyuan, and Qingyuan in the northern mountainous areas of the Pearl River Delta were the key ecological functional areas. The continuous mountainous forests acted as an ecological shelter and are important for maintaining a stable regional climate and environment. Therefore, the government restricted large-scale and high-intensity urbanization in these areas. 
The total investment in fixed assets was also an influential socioeconomic factor during the study period (Table 4 and Figure 4). As the financial support for the urban construction, the fixed asset investment was largely determined by the government in China [20]. In 2004, Guangzhou was elected as the host city of the 2010 Asian Games, and Foshan, Dongguan, and Shanwei were the co-host cities. According to statistics, the total investment in fixed assets was mainly concentrated in Guangzhou, Foshan and Dongguan during this period [22,24,25]. It was found that the urban-land expansion in these cities was rapid between 2005 and 2010. The preparation and construction of the relevant venues attracted a large amount of investment, promoted infrastructure construction in these cities, boosted their economic growth, and accelerated the expansion of urban land.

\section{Conclusions}

Based the land use data derived from RS imagery in 2000, 2005, 2010, and 2015, the spatial and temporal patterns of urban land expansion in the coastal urban agglomeration of the Pearl River Delta were analyzed in this study. The geographical detector was used to analyze the driving mechanism of the urban-land expansion. New knowledge related to the urban-land expansion intensity, expansion difference, and fractal dimension of the PRDUA was obtained. Moreover, the interactions between a complex set of factors of urban-land expansion were analyzed quantitatively, and the influence of policy factors was discussed based on the physical and socioeconomic factors.

The results indicated that the area of the urban land in the PRDUA showed a continuous increase, but the speed and intensity of urban expansion slowed down as compared that in the initial period. The cities with faster development were mainly concentrated in the south-central part of the PRDUA. The difference in urban-land expansion gradually diminished. Moreover, the fractal dimension of the different cities was consistent, thus demonstrating the coordinated development of the cities within the urban agglomeration. The spatial structure of the PRDUA has gradually changed from having a dual core to a multi-center feature.

The driving force analysis showed that the terrain conditions such as elevation and slope affect the potential, intensity, direction, and scale of urban-land expansion. However, in the short-term study, the influence of geographical factors on the urban spatial expansion did not change significantly. The social and economic factors are the core driving forces of the expansion of urban land in the PRDUA. Between 2000 and 2005, factors such as population growth and economic development played the largest role in the expansion of the urban land in the PRDUA. Before 2010, the distance to the core cities had a relatively high explanatory power for the expansion of urban land. However, the influence of the core cities on urban-land expansion decreased in the last period. In addition, the interactions between the distance to rivers and other factors always demonstrated a non-linear enhancement in the urban-land expansion. During 2000-2010, the average interaction between pairs of socioeconomic factors was the strongest, whereas that between pairs of physical factors was the weakest. However, the average interaction between socioeconomic factors and physical factors was stronger than that between the other two types of interaction during 2010-2015. Moreover, the number of pairs demonstrating nonlinear enhancement increased significantly during the study period, which indicated closer and more complicated interactions within the urban agglomeration. Policies such as the regional urban plans, environmental protection policies, and major events exhibited a considerable impact on the expansion of the PRDUA's urban land, but the effects of the macro and long-term plans usually took 5-10 years to become effective, and even more time to realize the final prospects.

Based on these findings, we opine that the next challenge is to continuously propose specific alternative strategies and future plans for optimizing the spatial pattern of urban expansion in coastal areas. The influence of individual factors and their interactions may be applied to forecast the future urban development in the study area and elsewhere in coastal urban areas.

Author Contributions: Conceptualization, H.J. and S.Z.; Formal analysis, Y.Y. and H.J.; Methodology, H.J. and S.Z.; Supervision, H.J.; Validation, H.J., S.Z. and W.J.; Visualization, Y.Y.; Writing-original draft, Y.Y.; Writing-review \& editing, Y.Y., H.J., S.Z. and W.J. All authors have read and agreed to the published version of the manuscript. 
Funding: This research was funded by Fundamental Research Funds for the Central Universities: 2020.

Conflicts of Interest: The authors declare no conflict of interest.

\section{References}

1. Scialabba, N. Integrated Coastal Area Management and Agriculture, Forestry and Fisheries; Food and Agriculture Org.: Rome, Italy, 1998.

2. Seto, K.C. Exploring the dynamics of migration to mega-delta cities in Asia and Africa: Contemporary drivers and future scenarios. Glob. Environ. Chang. 2011, 21, S94-S107. [CrossRef]

3. Brown, S.; Nicholls, R.J.; Woodroffe, C.D.; Hanson, S.; Hinkel, J.; Kebede, A.S.; Neumann, B.; Vafeidis, A.T. Sea-Level Rise Impacts and Responses: A Global Perspective; Finkl, C.W., Ed.; Coastal Hazards; Springer: Dordrecht, The Netherlands, 2013; pp. 117-149.

4. Seto, K.C.; Fragkias, M.; Güneralp, B.; Reilly, M.K. A Meta-Analysis of Global Urban Land Expansion. PLoS ONE 2011, 6, e23777. [CrossRef] [PubMed]

5. Li, H.; Peng, J.; Liu, Y.; Hu, Y. Urbanization impact on landscape patterns in Beijing City, China: A spatial heterogeneity perspective. Ecol. Indic. 2017, 82, 50-60. [CrossRef]

6. Guetté, A.; Gaüzère, P.; Devictor, V.; Jiguet, F.; Godet, L. Measuring the synanthropy of species and communities to monitor the effects of urbanization on biodiversity. Ecol. Indic. 2017, 79, 139-154. [CrossRef]

7. Kaushal, S.S.; McDowell, W.H.; Wollheim, W.M. Tracking evolution of urban biogeochemical cycles: Past, present, and future. Biogeochemistry 2014, 121, 1-21. [CrossRef]

8. Kennedy, C.A.; Stewart, I.; Facchini, A.; Cersosimo, I.; Mele, R.; Chen, B.; Uda, M.; Kansal, A.; Chiu, A.; Kim, K.-G.; et al. Energy and material flows of megacities. Proc. Natl. Acad. Sci. USA 2015, 112, 5985-5990. [CrossRef]

9. McGranahan, G.; Balk, D.; Anderson, B. The rising tide: Assessing the risks of climate change and human settlements in low elevation coastal zones. Environ. Urban 2007, 19, 17-37. [CrossRef]

10. He, C.; Liu, Z.; Tian, J.; Ma, Q. Urban expansion dynamics and natural habitat loss in China: A multiscale landscape perspective. Glob. Chang. Biol. 2014, 20, 2886-2902. [CrossRef]

11. Wu, W.; Zhao, S.; Zhu, C.; Jiang, J. A comparative study of urban expansion in Beijing, Tianjin and Shijiazhuang over the past three decades. Landsc. Urban Plan. 2015, 134, 93-106. [CrossRef]

12. Blaschke, T.; Hay, G.J.; Weng, Q.; Resch, B. Collective Sensing: Integrating Geospatial Technologies to Understand Urban Systems-An Overview. Remote Sens. 2011, 3, 1743-1776. [CrossRef]

13. He, C.; Tian, J.; Shi, P.; Hu, D. Simulation of the spatial stress due to urban expansion on the wetlands in Beijing, China using a GIS-based assessment model. Landsc. Urban Plan. 2011, 101, 269-277. [CrossRef]

14. Herold, M.; Scepan, J.; Clarke, K.C. The Use of Remote Sensing and Landscape Metrics to Describe Structures and Changes in Urban Land Uses. Environ. Plan. A Econ. Space 2002, 34, 1443-1458. [CrossRef]

15. Haas, J.; Ban, Y. Urban growth and environmental impacts in Jing-Jin-Ji, the Yangtze, River Delta and the Pearl River Delta. Int. J. Appl. Earth Obs. Geoinf. 2014, 30, 42-55. [CrossRef]

16. Ye, L. Urban transformation and institutional policies: Case study of mega-region development in China's Pearl River Delta. J. Urban Plan. Dev. 2013, 139, 292-300. [CrossRef]

17. Fang, C. Important progress and future direction of studies on China's urban agglomerations. J. Geogr. Sci. 2015, 25, 1003-1024. [CrossRef]

18. Shao, J.-A.; Wei, C.-F.; Xie, D.-T. An insight on drivers of land use change at regional scale. Chin. Geogr. Sci. 2006, 16, 176-182. [CrossRef]

19. Fang, S.; Gertner, G.Z.; Sun, Z.; Anderson, A.A. The impact of interactions in spatial simulation of the dynamics of urban sprawl. Landsc. Urban Plan. 2005, 73, 294-306. [CrossRef]

20. Ju, H.; Zhang, Z.; Zuo, L.; Wang, J.; Zhang, S.; Wang, X.; Zhao, X. Driving forces and their interactions of built-up land expansion based on the geographical detector-A case study of Beijing, China. Int. J. Geogr. Inf. Sci. 2016, 30, 1-20. [CrossRef]

21. National Bureau of Statistics of the People's Republic of China. China City Statistical Yearbook; China Statistics Press: Beijing, China, 2001. (In Chinese)

22. National Bureau of Statistics of the People's Republic of China. China City Statistical Yearbook; China Statistics Press: Beijing, China, 2016. (In Chinese) 
23. Zhang, Z.; Wang, X.; Zhao, X.; Liu, B.; Yi, L.; Zuo, L.; Wen, Q.; Liu, F.; Xu, J.; Hu, S. A 2010 update of National Land Use/Cover Database of China at 1:100,000 scale using medium spatial resolution satellite images. Remote Sens. Environ. 2014, 149, 142-154. [CrossRef]

24. National Bureau of Statistics of the People's Republic of China. China City Statistical Yearbook; China Statistics Press: Beijing, China, 2006. (In Chinese)

25. National Bureau of Statistics of the People's Republic of China. China City Statistical Yearbook; China Statistics Press: Beijing, China, 2011. (In Chinese)

26. Chen, Y.; Wang, J.; Feng, J. Understanding the Fractal Dimensions of Urban Forms through Spatial Entropy. Entropy 2017, 19, 600. [CrossRef]

27. Wang, H.; Zhang, B.; Liu, Y.L.; Liu, Y.F.; Xu, S.; Deng, Y.; Zhao, Y.; Chen, Y.; Hong, S. Multi-dimensional analysis of urban expansion patterns and their driving forces based on the center of gravity-GTWR model: A case study of the Beijing-Tianjin-Hebei urban agglomeration. Acta Geogr. Sin. 2018, 73, 1076-1092. (In Chinese)

28. Wang, J.; Xu, C. Geodetector: Principle and prospective. Acta Geogr. Sin. 2017, 72, 116-134.

29. Wang, J.; Li, X.; Christakos, G.; Liao, Y.; Zhang, T.; Gu, X.; Zheng, X. Geographical Detectors-Based Health Risk Assessment and its Application in the Neural Tube Defects Study of the Heshun Region, China. Int. J. Geogr. Inf. Sci. 2010, 24, 107-127. [CrossRef]

30. Shu, B.; Zhang, H.; Li, Y.; Qu, Y.; Chen, L. Spatiotemporal variation analysis of driving forces of urban land spatial expansion using logistic regression: A case study of port towns in Taicang City, China. Habitat Int. 2014, 43, 181-190. [CrossRef]

31. Braimoh, A.K.; Onishi, T. Spatial determinants of urban land use change in Lagos, Nigeria. Land Use Policy 2007, 24, 502-515. [CrossRef]

32. Ma, Y.; Xu, R. Remote sensing monitoring and driving force analysis of urban expansion in Guangzhou City, China. Habitat Int. 2010, 34, 228-235. [CrossRef]

33. Li, X.; Zhou, W.; Ouyang, Z. Forty years of urban expansion in Beijing: What is the relative importance of physical, socioeconomic, and neighborhood factors? Appl. Geogr. 2013, 38, 1-10. [CrossRef]

34. Wu, K.Y.; Zhang, H. Land use dynamics, built-up land expansion patterns, and driving forces analysis of the fast-growing Hangzhou metropolitan area, eastern China (1978-2008). Appl. Geogr. 2012, 34, 137-145. [CrossRef]

35. Wang, J.F.; Liu, X.; Christakos, G.; Liao, Y.L.; Gu, X.; Zheng, X.Y. Assessing local determinants of neural tube defects in the Heshun Region, Shanxi Province, China. BMC Public Health 2010, 10, 52. [CrossRef]

36. Liu, J.; Zhang, Z.; Xu, X.; Kuang, W.; Zhou, W.; Zhang, S.; Li, R.; Yan, C.; Yu, N.; Wu, S.; et al. Spatial patterns and driving forces of land use change in China during the early 21st century. J. Geogr. Sci. 2010, 20, 483-494. [CrossRef]

(C) 2019 by the authors. Licensee MDPI, Basel, Switzerland. This article is an open access article distributed under the terms and conditions of the Creative Commons Attribution (CC BY) license (http://creativecommons.org/licenses/by/4.0/). 